\title{
MANAJEMEN DAKWAH BIL LISAN PERSPEKTIF HADITS
}

\section{Rofiq Hidayat}

Dosen Program Studi Manajemen Pendidikan Islam

Fakultas Tarbiyah dan Ilmu Keguruan Institut Agama Islam Negeri Jember elishaqy@yahoo.com

\begin{abstract}
In this paper, the author presents a study of the management of oral preaching perspective on hadith. The study discussed is about how the concept of oral preaching management is based on the traditions of the Prophet; besides that the author intends to explore the relation of the hadiths to the theory of management experts. This paper presents the notion of preaching management; In addition to the understanding of preaching management and the kinds of media through oral, it will also be explained about the concept of management of oral preaching in the form of planning, implementation, and evaluation. The results of this study are: (1) Planning, Rasulullah recommends to develop a strategy of da'wah which if it is not difficult, can provide excitement, and does not make the objects we invite do not leave us. (2) Implementation, the Prophet guided da'i that in delivering his preaching he must avoid words that came out of haq (hoax), hate speech, and arrogant (arrogant). (3) Evaluation, the Rasulullah told us to evaluate ourselves for what has been done and still control our passions.
\end{abstract}

Keywords: management, da'wah, hadith

\section{Pendahuluan}

Salah satu kewajiban orang berilmu adalah mengamalkan ilmu, salah satu cara mengamalkan adalah melalui dakwah. Bahkan metodenya bisa dengan berbagai cara. Tentang kewajiban dakwah, Allah berfirman dalam surat AnNahl:125:

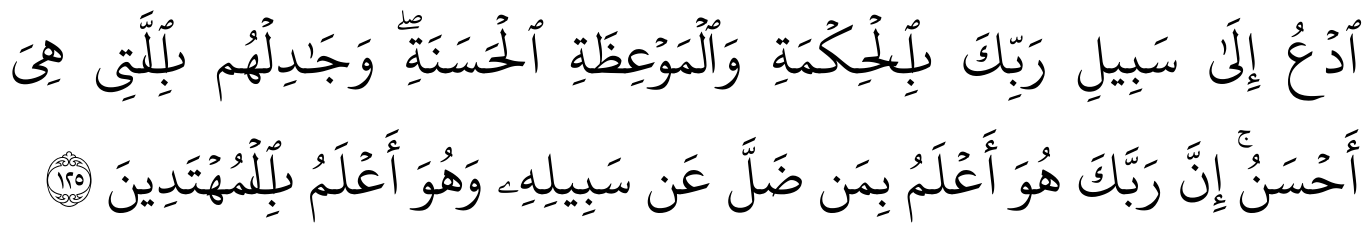

Artinya:

"Serulah (manusia) kepada jalan Rabbmu dengan hikmah dan pelajaran yang baik dan bantahlah mereka dengan cara yang lebih baik. Sesungguhnya Rabbmu, Dialah yang 
lebih mengetahui tentang siapa yang tersesat dari jalan-Nya dan Dialah yang lebih mengetahui orang-orang yang mendapat petunjuk." (QS. an-Nahl: 125)

Dari ayat tersebut, bisa kita simpulkan bahwa menyeru (berdakwah) kepada manusia adalah salah satu perintah Allah. Karena itu diperlukan metode yang baik agar isi dakwah yang disampaikan bisa diterima dengan baik oleh khalayak. Dalam ayat tersebut metode yang bisa dipakai salah satunya dengan cara hikmah, pelajaran yang baik, dan diskusi.

Selain Allah, Rasulullah juga memerinahkan untuk berdakwah dalam haditsnya:

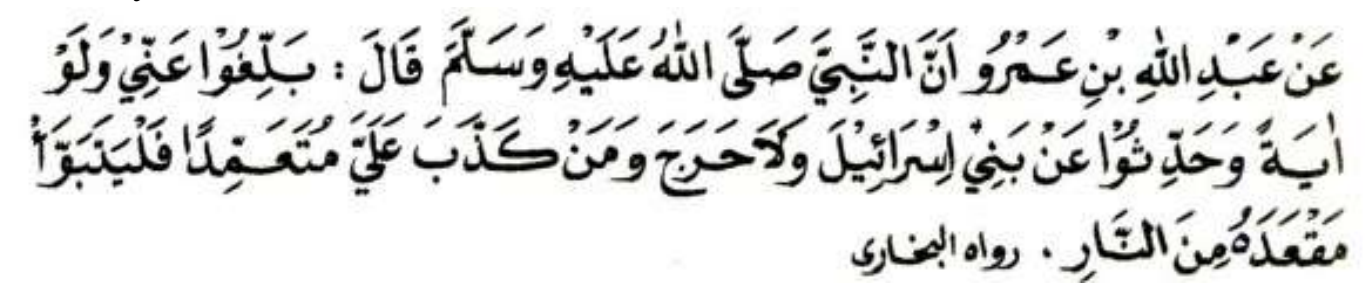

Artinya:

"Dari Abdullah ibn Amr bahwa Nabi saw. bersabda, "Sampaikanlah dariku walaupun hanya satu ayat. Ceritakanlah apa yang telah aku beritahukanmengenai Bani Israil karena demikian itu tidak berdosa. Barang siapa sengaja berdusta tentang aku, kelak tempatnya di neraka." (HR. Bukhari no. 3274)

Dalam hadits tersebut Rasulullah memerintahkan untuk menyampaikan meski hanya satu kata. Juga nabi melarang untuk berdusta terhadap apa yang disampaikan. Hal itu tentunya menjadi landasan dalam berdakwah,yaitu landasan jujur dalam segala metode dakwah.

Namun metode saja tidak cukup,dakwah tidak akan bisa menjangkau umat jika tidak kelola dengan baik. Karena itulah segala sesuatu harus direncanakan dengan baik, termasuk dalam berdakwah. Kegiatan dakwah yang baik adalah apabila kegiatan itu tepat sasaran secara efektif dan efesien. Oleh karena itu dakwah harus diorgansiasi secara matang agar tidak dilakukan secara asal-asalan dan serampangan. Karena pada prinsipnya kegiatan dakwah dapat berjalan secara efektif bilamana apa yang menjadi tujuan dapat benar-benar tercapai, atau apabila kegiatan yang telah terorganisir dilaksanakan sesuai dengan prinsip-prinsip manjemen dakwah.

Ahmad Atabik memaparkan, pengorganisasian dakwah harus dilaksanakan menimbang bahwa kegiatan ini tidak hanya mencakup isi ajakan (materi dakwah) semata, namun juga berkaitan dengan subjek atau pelaku dakwah (da'i), dan juga objek atau peserta dakwah (mad'u). Selain ketiga hal di atas, pelaksanaan dakwah juga membutuhkan metode penyampaian dakwah. 
Metode penyampaian ini sejatinya telah diajarkan oleh al-Qur'an al-Karim dan juga oleh Rasulullah Saw. melalui sabda-sabdanya. Apabila pengorganisasian terhadap empat komponen dakwah di atas, maka kegiatan dakwah akan membuahkan hasil yang diharapkan. ${ }^{1}$ Untuk menuju ke hasil tersebut, da'i harus memiliki landasan konsep yang matang dalam bentuk manajemen dakwah.

Dalam jurnal ini, penulis bermaksud mengeksplorasikan manajemen dakwah perspektif hadits. Mengingat dakwah memiliki banyak media, maka penulis memfokuskan tulisan ini ke arah media dakwah bil lisan. Tulisan ini akan menyuguhkan tentang pengertian manajemen dakwah bil lisan; pada kesempat ini akan dibahas pula bagaimana hadits juga secara implisit telah membicarakan tentang menajemen dakwah ini. Selain pengertian manajemen dakwah, akan pula dipaparkan tentang konsep perencanaan, implementasi dan evaluasi dalam manajemen dakwah bil lisan.

\section{Pembahasan}

\section{Pengertian Manajemen Dakwah}

Kata menajemen, secara etimologis, berasal dari Bahasa Inggris, management, yang berarti ketatalaksanaan, tata pimpinan, dan pengelolaan. Oxford mendefiniskan manajemen sebagai the act of running and controlling, yang berarti kegiatan menjalankan dan mengontrol. ${ }^{2}$ Sementara dalam Bahasa Arab, manajemen biasa disebut dengan at-tanzhim dan at-takhthith. Dengan demikian, secara bahasa, manajemen berarti suatu proses yang diterapkan oleh individu atau kelompok dalam upaya-upaya koodinasi untuk mencapai suatu tujuan $^{3}$

Sedangkan secara terminologis, manajemen mempunyai banyak pengertian, Stephen P. Robbins menuliskan bahwa:"management involves coordinating and overseeing the work activities of others so that reviews their activities are completed efficiently and effectively. ${ }^{4}$

Berbeda dengan Robbins, Griffin juga menambahkan mengenai definisi manajemen:

"The management is all organizations use four basic kinds of resources from their

${ }^{1}$ Ahmad Atabik, Manajemen Dakwah Perspektif Al-Qur'an, Jurnal TADBIR Vol. 1, No. 1, Juni 2016, (STAIN Kudus, 2016), hal. 1

2 A.S. Hornby. Oxford Advanced Learner's Dictionary Of Current English Seventh Edition.(Oxford:Oxford University Press, 2005), Hal. 896.

${ }^{3}$ M. Munir dan Wahyu Ilaihi.. Manajemen Dakwah. (Jakarta:Prenada Media. Munir dan Ilaihi, 2006), 9

4 Stephen P. Robbins \& Mary Coulter. Management. Elevent Edition, (New Jersey: Pearson Education Publishing inc, 2012), hal. 8 
environtment: human, financial, physical, and information. Human resources include managerial talent and labor. Financial recources are the capital used by the organization to finance both on going and long-term operations. Physical recources include raw materials, office and production facilities, and equipment. Information resources are usable data is needed to the make effective decisions. In other words, management is series of activities (including planning and decisionmaking, organizing, leadership, and control) were directed at organizational resources (human, financial, physical, and information) in order to achieve organizational goals effectively and efficiently. "5

Dari kedua pendapat ahli tersebut memiliki beberapa perbedaan, jika Robbins kegiatan manajemennya cenderung lebih ke koordinasi dan pengawasan, maka Griffin lebih kompleks lagi dengan mencakupkan sumber daya manusia, keuangan, fisik, dan informasi.

George R. Terry memaparkan bahwa manajemen adalah suatu proses atau kerangka kerja, yang melibatkan bimbingan atau pengarahan suatu kelompokorang-orang ke arah tujuan-tujuan organisasional atau maksudmaksud yang nyata. ${ }^{6}$

Munir menambahkan bahwa manajemen memilki pengertian serangkaian kegiatan merencanakan, menggerakkan, mengorganisasikan, mengendalikan dan mendayagunakan sumber daya manusia, saran dan prasarana untuk mencapai tujuan organisasi yang telah ditetapkan secara efektif dan efesien. Selain itu, pengertian manajemen juga sangat ditekankan pada aspek pengaturan aktivitas fungsi dari sumber daya manusia. ${ }^{7}$ Dari pengertian manajemen dari para ahli tersebut, dapat kita simpulkan bahwa manajemen adalah kegiatan mengelola suatu dengan memanfaatkan sumber daya yang ada untuk mencapai tujuan bersama yang efektif dan efisien.

Sedangkan dakwah menurut Anis, secara etimologi berasal dari kata دعايدعودعوة bentuk masdarnya mempunyai arti ajakan, seruan atau panggilan. ${ }^{8}$ Namun Jum'ah Amin Abdul Aziz ${ }^{9}$ menjelaskan bahwa kata dakwah yang berarti seruan atau panggilan mempunyai padanan lain dalam

${ }^{5}$ Ricky W. Griffin. Management Seventh Edition. Boston Houston Mifflin Company, 2002), hal. 4

6 George R. Terry \& Leslie W. Sue, Dasar-Dasar Manajemen. Terj. G.A Ticoalu. (Jakarta:PT Bumi Aksara, 1992), hal. 1.

7 M. Munir dan Wahyu Ilaihi.. Manajemen Dakwah. (Jakarta:Prenada Media., 2006), hal. 9

8 Ibrahim Anis et. All, Al-Mu'jam al-Wasith, (Mesir: Dar'1 Ma'arif, 1972 ), Jilid ke-1, cet. ke- 2, hal. 286

9 Jum'ah Amin Abdul Aziz,. Fiqih Dakwah. Solo: Era Intermedia, 2010), hal. 24. 
Bahasa Arab, semisal:

1. An-Nida, berarti panggilan dan seruan.

2. Ad-du'a, semisal ad-du'a ila asy-syai' berarti seruan kepada sesuatu.

3. Ad-Da'wat ila qadhiyat, berarti menegaskannya atau membelanya, baik terhadap yang benar maupun yang salah, positif maupun yang negatif.

Jum'ah Amin Abdul Aziz juga mendefinisikan dakwah dengan mengambil pengertian dakwah dalam al-Qur'an (da'wah) dengan berbagai derivasinya sering diulang dalam al-Qur'an, semisal dalam QS. Yusuf: 33

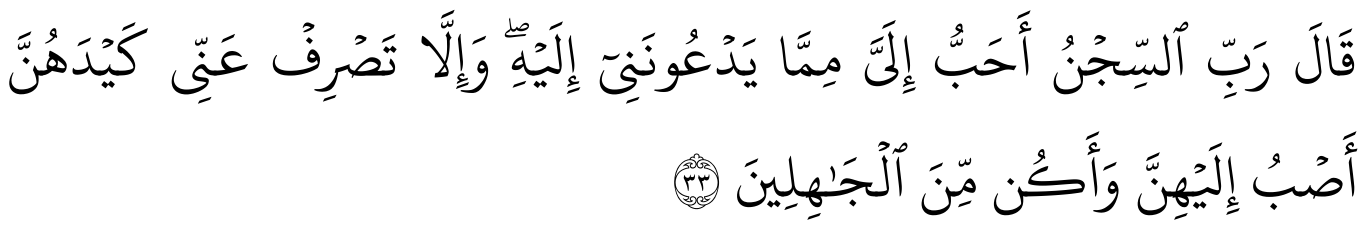

Artinya:

"Yusuf berkata: "Wahai Tuhanku, penjara lebih aku sukai daripada memenuhi ajakan mereka kepadaku".

Ayat lain yang berbicara tentang da'wah adalah dalam QS. Yunus: 25.

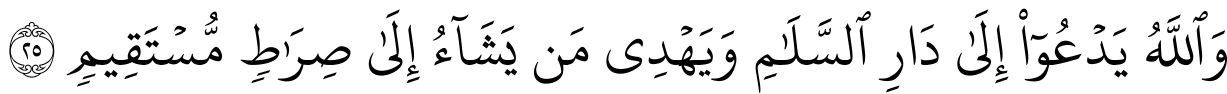

Artinya:

"Allah menyeru (manusia) ke Darussalam (surga), dan menunjuki orang yang dikehendaki-Nya kepada jalan yang lurus (Islam)".

Dari kedua ayat tersebut bisa kita simpulkan bahwa dakwah (ajakan atau seruan) bersifat satu arah. Artinya tidak ada keharusan orang yang diajak harus ikut semuanya. Jadi kewajiban da'i hanya sebatas mengajak tanpa memaksa. sementara I'anatut Thoifah mengkhususkan dakwah hanya pada kebaikan dan petunjuk Allah SWT. Maksudnya menyeru mereka kepada kebiasaan yang baik dan melarang mereka dari kebiasaan buruk supaya mendapatkan keberuntungan di dunia dan akhirat. ${ }^{10}$ Artinya, ajakan yang mengajak pada keburukan bukanlah bagian dari dakwah bahkan meski hal itu dilakukan oleh da'i sekalipun.

Dengan demikian, gabungan kata manajemen dan dakwah menjadi sebuah bentuk idlafiyah mempunyai maksud: proses perencanaan tugas, mengelompokkan tugas, menghimpun dan menempatkan tugas dan kemudia menggerakkan kea rah pencapaian tujuan dakwah. Dengan adanya perencaan

10 I'anatut Thoifah. Manajemen Dakwah Sejarah dan Konsep. (Malang:Madani Press, 2015), hal. 5. 
dalam berdakwah ini, maka dakwah tidak dipandang dalam objek ubudiyyah semata, namun juga merupakan bentuk implementasi dari berbagai macam profesi. ${ }^{11}$ Sebab, apabila kegiatan dakwah ini dapat dilembagakan dan direncakan sedemikian rupa (dengan baik), maka tujuan dakwah yang telah direncanakan akan dapat tercapai sesuai dengan targetnya.

\section{Media Dakwah bil Lisan}

Dalam menyampaikan Dakwah, dai bisa menggunakan bermacammacam media. Samsul Munir Amin menuliskan bahwa terdapat tiga macam media dakwah yang bias digunakan dalam menyampaikan metode dakwah, yaitu bil Hal (dakwah dengan aktivitas dan amal nyata), bil Qalam (dakwah melalui tulisan atau karya nyata, seperti jurnal, buku, membangun sekolah, dan lainnya), dan bil Lisan (dakwah yang disampaikan melalui lisan seperti khutbah, ceramah, maupun penjelasan guru dalam kelas atau ustadz dalam majlis taklim).12 Sementara Hamzah Yaqub menyebutkan bahwa ada lima jenis media dakwah, yaitu:

1. Lisan, seperti pidato, ceramah, bimbingan, dan sebagainya.

2. Tulisan, seperti majalah, surat kabar, buletin, dan sebagainya.

3. Lukisan, seperti gambar, karikatur, dan sebagainya

4. Audio visual, seperti televisi, internet, dan lainnya dengan tujuan agar ceramah tidak kaku dan membosankan.

5. Akhlak, yakni menyampaikan dakwah dalam bentuk perbuatan nyata, lagsung praktik dan tidak banyak teori. ${ }^{13}$

Sedangkan menurut Siti Uswatun Khasanah, dari kelima hal tersebut dapat dipersempit menjadi tiga media, yaitu:

1. Spoken word, media dakwah berbentuk ucapan atau bunyi yang ditangkap dengan indera telinga seperti audio, telepon, dan lainnya

2. Printed writing, berbentuk tulisan, gambar lukisan dan sebagainya yang dapat ditangkap dengan mata.

3. The audio visual, berbentuk gambar hidup yang dapat didengar sekaligus dilihat, seperti televisi, video, film, dan sebagainya. ${ }^{14}$

Dari ketiga paparan mengenai media dakwah tersebut, terdapat perbedaan makna dakwah bil lisan. Jika menuru Hamzah Yaqub dan Siti

${ }^{11}$ M. Munir dan Wahyu Ilaihi.. Manajemen Dakwah. (Jakarta:Prenada Media. Munir dan Ilaihi, 2006), hal. 11

12Samsul Munir Amin. Rekonstruksi Pemikiran Dakwah Islam, (Jakarta: Amzah:2018), hal. 11-12.

13 Dalam Iánatut Thoifah, Manajemen Dakwah Sejarah dan konsep, hal.55.

14 Dalam Iánatut Thoifah, ibid. Hal. 56. 
Uswatun Hasanah bahwa dakwah bil lisan adalah dakwah yang disampaikan oleh lisan yang bisa secara langsung. Dalam artian mad'u harus berhadapan dengan da'i diwaktu yang sama dan tempat yang sama tanpa perantara. Karena jika direkam lalu disampaikan melalui perantara lain, misalnya televisi, LCD proyektor, atau streaming internet, maka media dakwah berubah menjadi media lain. Namun penulis lebih setuju jenis media menurut Samsul Munir Amin, karena sekalipun melalui televisi, atau streaming internet, namun media awal untuk menyampaikan tetap berasal dari lisan sang da'i. Sedangkan streaming internet adalah media kedua yang tetap harus bergantung pada media awal melalui dakwah bil lisan dari sang da'i.

Sementara Ibrahim bin Abdullah al Muthlaq memaparkan jika ditilik dari sejarah, rasulullah menggunakan 4 jenis tahapan dalam sarana dakwah, yaitu: perkataan, ekspedisi militer, korespondensi, dan penerimaan delegasi dan pengiriman duta. ${ }^{15}$ Dalam menyampaikan dakwah baik di Mekkah, Thaif, dan Madinah, Nabi sering menggunakan sarana lisan dalam menyampaikan dakwah. Korespondensi juga merupakan perpanjangan tangan dakwah bil lisan melalui sarana tulisan yang dituliskan oleh para sahabat. Sementara ekspedisi militer lebih ke arah dengan membebaskan umat dari penguasa yang sewenang-wenang yang membantuk menyebarkan dakwah islam secara kuantitatif. Sedangkan tahapan penerimaan delegasi dan pengiriman duta lebih ke arah bagaimana manajemen Nabi dalam menyebarkan dakwah secara kualitatif.

Sebagai sarana dakwah yang vital, lisan adalah sarana bawaan yang dimiliki setiap orang kecuali orang yang bisu. Allah sangat menekankan Rasulullah dalam menggunakan lisan sebagai sarana dakwah. Lebih dari 300 ayat Al Quran menggunakan lafal Qul (katakanlah) sebagai perintah Allah pada Rasulullah untuk menggunakan lisannya untuk menyampaikan risalah. Sedemikian pentingnya hingga Allah mengutus rasul dengan bahasa kaumnya dalam menjelaskan risalahnya.

\section{Manajemen Dakwah bil Lisan perspektif hadits}

Berdasarkan pemaparan mengenai pengertian manajemen dakwah bil lisan, dapat kita ambil kesimpulan bahwa manajemen dakwah bil lisan dalam hal ini erat kaitannya dengan penyampaian dai melalui lesan. Dalam hal ini beberapa contohnya adalah ceramah kyai dalam pengajian atau majlis taklim, khutbah jumat, atau diskusi debat.

15 Ibrahim bin Abdullah al Muthlaq. At-Tadarruj Fi Da'wah an-Nabi Sallallahu Alaihi wa Sallam. Terj. Abdul Majid (Yogyakarta:Pustaka Insan Madani, 2008), Hal 53-75 
Dalam manajemen dakwah bil lisan, penting bagi kita untuk mengatur apa yang akan kita sampaikan. Jika tidak, maka apa yang menjadi tujuan dakwah tidak akan tersampaikan. Ahidul Asror menuliskan bahwa tujuan dakwah adalah tercapainya kebahagiaan hidup di dunia dan akhirat. Kebahagiaan tersebut dapat terwujud apabila manusia melakukan penghayatan dan pengamalan ajaran Islam dalam seluruh aspek kehidupan ${ }^{16}$, salah satunya melalui hadits. Karena itu perlunya manajemen dakwah yang berlandaskan Islam melalui kajian terhadap hadits Nabi. Dalam hal ini Rasulullah bersabda:

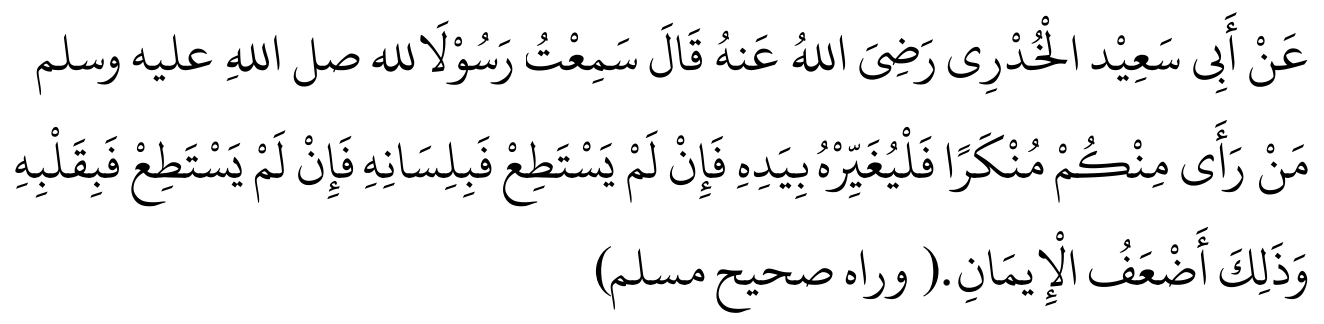

Artinya: "Dari Abi Said al-Khudri ra. berkata, saya mendengar Rasulullah saw. bersabda:" Barangsiapa yang melihat kemungkaran, maka cegahlah dengan tanganmu, apabila belum bisa, maka cegahlah dengan mulutmu, apabila belum bisa, cegahlah dengan hatimu, dan mencegah kemungkaran dengan hati adalah pertanda selemah-lemah iman" (HR. Muslim No. 78)

Sanad hadits ini jika merujuk pada kitab syarag shahih muslim adalah berkata Abu Bakar bin Abi Syaibah, berkata Waki' dari Sufyan, berkata Muhammad bin Al Mutsanna, berkata Muhammad bin Ja'far, berkata Syu'bah, keduanya (meriwayatkan dari Qais bin Muslim, dari Thariq bin Syihab, lalu menyambung ke Abi Said al-Khudri RA.

Adapun yang meriwayatkan hadits ini berdasarkan Mu'jam $\mathrm{Al}$ Mufahrosh adalah Muslim (Bab Iman no.78 dan Bab Rukya no. 6-2), Bukhori (Bab Ilmu no. 28, taghyir no. 4,10,26,47), Darimi (Bab Mulaham no. 18 dan Tibb no. 24), Turmudzi (Bab Rukya No. 1,5,7,10) Nasai (Bab Iman no.18), Duruquthni (Bab Rukya no.4,6) Thabrani (Bab Rukya no.4), dan Hambali (no. 2, 104, 3, 20). ${ }^{17}$ Namun menurut Imam Nawawi hadits ini diriwayatkan pula oleh At-Turmudzi (IV/2172), Nasa'i (VIII/111), Abu Dawud (IV/4340) dan

\footnotetext{
${ }^{16}$ Ahidul Asror, Paradigma Dakwah Konsepsi dan Dasar Pengembangan Ilmu, Yogyakarta:LKIS, 2018), Hal. 38.

17 Arent Jan Weinsink.Mu'jam Mufahras li Alfadhil Hadits An Nabawi (Leiden: E.J Brill,1936), hal. 200.
} 
Ibnu Majah (II/4013). ${ }^{18}$

Berdasarkan hadits riwayat muslim di awal dijelaskan mengenai tiga metode yang diterapkan, yaitu bil yadi (dengan tangan), bil lisan (dengan perkataan), dan bil qalbi (dengan hati). Metode dalam hadits tersebut bisa kita maknai secara harfiah, namun bisa kita implementasikan dalam bentuk lain, yaitu:bil yadi (dengan kekuasaan), bil lisan (dengan media), dan bil qalbi (dengan doa). Artinya, dengan apa yang dimiliki, da'i harus bisa mengimplementasikan metodenya dengan baik sesuai karakteristik umat.

Jika ditilik dari asbabul wurud-nya, hadits ini diucapkan Abi Said berkaitan dengan Khalifah Marwan yang pada saat khutbah hari raya akan melaksanakan khutbah sebelum sholat id, lalu dihentikan oleh seorang lakilaki yang mengatakan bahwa sejak dahulu para khalifah melakukan sholat sebelum khutbah, lalu dibantah oleh Marwan bahwa hal itu telah ditinggalkan, lalu Abi Said menengahi melalui hadits tersebut. ${ }^{19}$ Dari peristiwa tersebut, bisa kita ambil kesimpulan tahapan Abi Said yang menyeru dakwah untuk amar ma'ruf nahi munkar. Sehingga apa yang ia dengar dari Rasulullah langsung diterapkan oleh Abi Said.

Selanjutnya Imam Nawawi menerangkan bahwa dakwah amar ma'ruf nahi munkar hukumnya fardu kifayah, namun jika tidak dilakukan oleh semua orang maka menjadi berdosa, maka dakwah tersebut hukumnya menjadi wajib. Karena itulah diperlukan tahapan dalam melakukan dakwah.

Dari hadits tersebut, terdapat tahapan-tahapan yang bisa diterapkan dalam manajemen dakwah, yaitu merencanakan dengan menggunakan suatu metode, dalam hal ini nabi memberikan tiga strategi, lalu mengimplementasikan apa strategi yang sudah disiapkan, jika gagal, dievaluasi ulang untuk diterapkan kembali dengan cara yang berbeda. Intinya, berdasarkan hadits tersebut, terdapat tiga tahapan dalam manajemen dakwah, yaitu perencanaan, implementasi, dan evaluasi.

\section{a. Perencanaan}

Perecanaan penting dalam sebuah dakwah. Menurut Zainal Arifin, perencanaan jika dirunut dalam bahasa Inggris disebut planning, sedangkan dalam bahasa arab disebut At Takhtit (التخطيط),yang merupakan bentuk

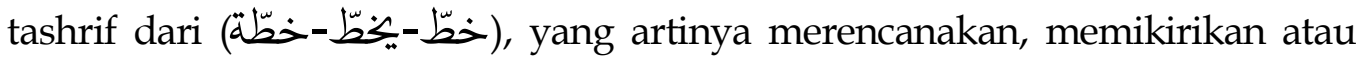

18 Imam Nawawi, Syarah Shahih Muslim, terj. Wawan Djunaedi Soffandi (Jakarta:Mustaqim, 1994), Hal. 515

${ }^{19}$ Ibid. Hal. 516-520. 
(التخطيط) juga diartikan sebagai penggarisan. Berdasarkan pengertian ini, perencanaan merupakan kegiatan merencanakan, memikirkan, atau menggariskan sesuatu untuk dilaksanakan di masa yang akan datang. ${ }^{20}$ Dalam hal ini dai harus membuat perencaan terhadap apa yang akan disampaikannya.

Strategi adalah bagian dari perencanaan jadi penting bagi seorang da'i untuk menyusun strategi. Secara histori Rasulullah juga menggunakan strategi dalam berdakwah di Mekkah, yaitu berdakwah secara sembunyi-sembunyi selama tiga tahun dan berdakwah secara terang-terangan. Hal itu dilakukan Rasulullah karena melihat kondisi masyarakat Mekkah21. Strategi berbeda diterapkan saat Rasulullah di Madinah yang diterapkan melalui mempersaudarakan kaum Muhajarin dan Anshor, pendirian masjid-masjid, dan jihad untuk membela diri. ${ }^{22}$ Dari strategi rasulullah tersebut kita bisa mengambil kesimpulan bahwa kita harus memperhatikan objek yang akan kita ajak, baru kemudian menentukan langkah yang akan diambil. Rasulullah bersabda:

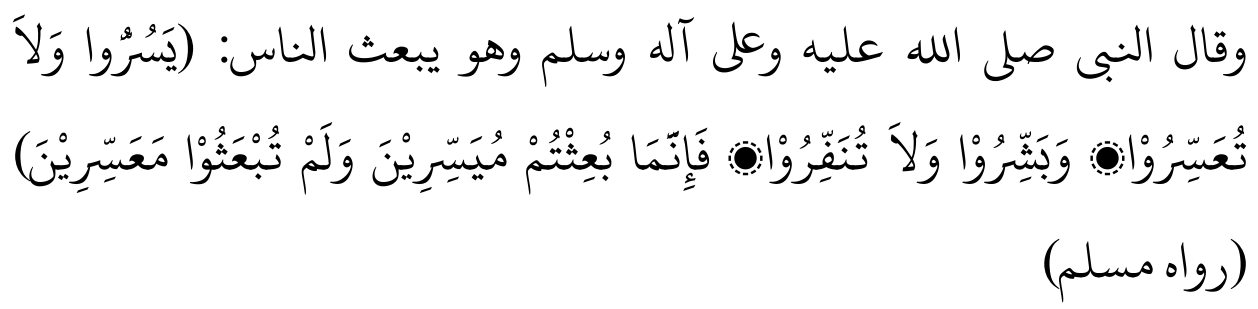

Artinya:

Nabi SAW bersabda dan beliau menyampaikannya pada manusia: "Hendaklah kalian bersikap memudahkan dan jangan menyulitkan. Hendaklah kalian menyampaikan kabar gembira dan jangan membuat mereka lari, karena sesungguhnya kalian diutus untuk memudahkan dan bukan untuk menyulitkan."(HR. Muslim no. 69)

Hadits tersebut terdapat dalam Shahih Bukhari Bab Ilmu no. 4. Bab mafaza no. 60 dan bab Adab no. 80, sedangkan dalam Shahih Muslim terdapat dalam bab Jihad no. 4. Hadits ini juga terdapat dalam Sunan Abu Daud bab

20 Zainal Arifin, Tafsir Ayat-Ayat Manajemen, (Yogyakarta:Prodi Manajemen Pendidikan Islam UIN Sunan Kalijaga), hal. 117

21 Hasan Abdullah Hasan, Sejarah dan Kebudayaan Islam, terj, H. A. Bahaudin, (Jakarta: Kalam Mulia, 2002), hal. 144-149

22 Ibid. Hal.168-195. 
adab no. 17 dan Ahmad Ibnu Hanbal di jilid 1, 2, dan $4 .{ }^{23}$

Ibnu Hajar Al Asqalani dalam Fathul Baari menerangkan bahwa faidah

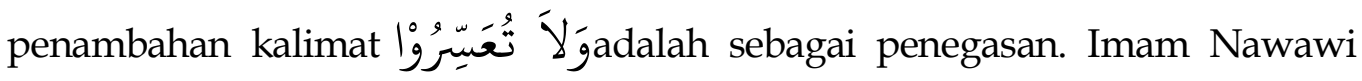
berkata. "Jika hanya menggunakan katal' يَسِّرو yang hanya memberikan kemudahan sekali dan sering mempersulit orang lain termasuk dalam hadits tersebut. Oleh karena itu, Rasulullah bersabda, تُعَسِّروُوْا (Janganlah mempersulit) dengan maksud untuk mengingatkan, bahwa memberikan kemudahan kepada orang lain harus selalu dilakukan dalam setiap situasi dan kondisi. Demikian pula dengan sabda Nabi, setelah kata

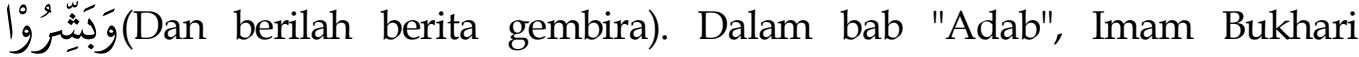

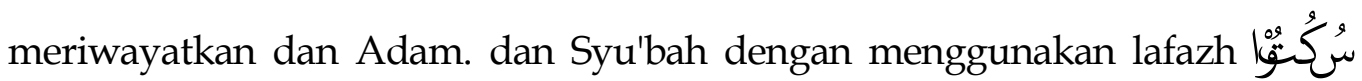

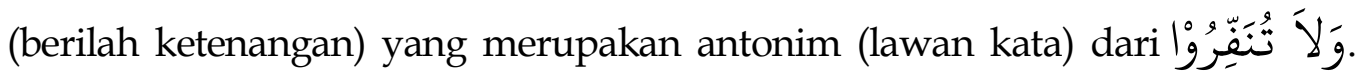

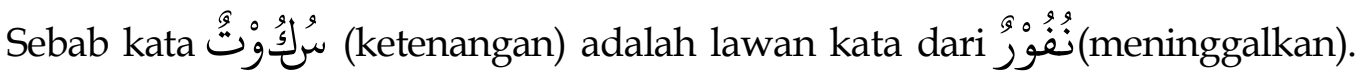
Akan tetapi karena menyampaikan kabar buruk pada awal sebuah pengajaran dapat menyebabkan orang tidak menghiraukan nasihat yang akan diberikan kepadanya, maka kata الَبشَارَةُونة(berita gembira) di sini diikuti dengan kata تَنَفْنِ(meninggalkan). ${ }^{24}$

Ibnu Hajar Al Asqalani menambahkan maksud dari hadits ini adalah; 1. Kita harus berlaku ramah kepada orang yang baru memeluk Islam dan tidak mempersulitnya. 2. Lemah lembut dalam melarang perbuatan maksiat agar dapat diterima dengan baik. 3. Menggunakan metode bertahap dalam mengajarkan suatu ilmu, karena segala sesuatu jika diawali dengan kemudahan, maka akan dapat memikat hati dan menambah rasa cinta. Berbeda halnya jika pengajaran itu dimulai dengan kesulitan.

Dari hadits tersebut Rasulullah menganjurkan kepada kita untuk

23 Arent Jan Weinsink.Mu'jam Mufahras li Alfadhil Hadits An Nabawi jilid 4 (Leiden: E.J Brill,1936), hal. 21.

${ }^{24}$ Ibnu Hajar Al Asqalani. Fathul Baari Syarah Shahih Al Bukhari jilid 1. Terj. Ghazirah Abdi Ummah. (Jakarta:Pustaka Azzam, 2002), hal. 309. 
menyusun strategi dakwah yang sekiranya tidak menyulitkan, bisa memberi kegembiraan, dan tidak membuat obyek yang kita ajak tidak pergi meninggalkan kita. Dalam hal ini, perencanaan yang dimaksudkan nabi adalah membuat rambu-rambu dalam berdakwah dalam sebuah rencana jangka pendek. Berbeda dengan hadits tersebut, Terry mengungkapkan bahwa yang lebih utama dalam perencanaan adalah menentukan tujuan (dalam hal ini adalah tujuan jangka panjang), karena menurut Terry, titik tolak proses manajemen adalah menentukan "objectives" atau tujuan-tujuan organisasi. 25 Dalam hal ini, menurut penulis, kita tidak bisa menerapkan teori Terry dalam manajemen dakwah karena yang diutamakan Terry adalah tujuan organisasi atau golongan, padahal dalam dakwah, yang harus diutamakan adalah pesan ilahi tanpa mementingkan golongan.

Agar tujuan dakwah dapat disampaikan, maka sejak awal dai perlu untuk menata hati agar motif berdakwahnya sesuai dengan tujuan dakwah. Ahidul Asror memaparkan bahwa motif bagi juru dakwah yaitu pertama, ikhlas karena Allah. Kedua, tidak berharap balasan pahala dari manusia. Ketiga, melaksanakan perintah serta takut ancaman. ${ }^{26}$

\section{b. Implementasi}

Dalam mengimplementasikan strategi dakwah bil lisan, Rasulullah menekankan untuk selalu belaku santun dan tidak berkata kasar. Selain dalam al Quran, dalam hadits Rasulullah juga memerintahkan untuk mengatur katakata sebelum kita ucapkan. Tak terkecuali dalam berdakwah. Seperti tertuang dalam haditsnya:
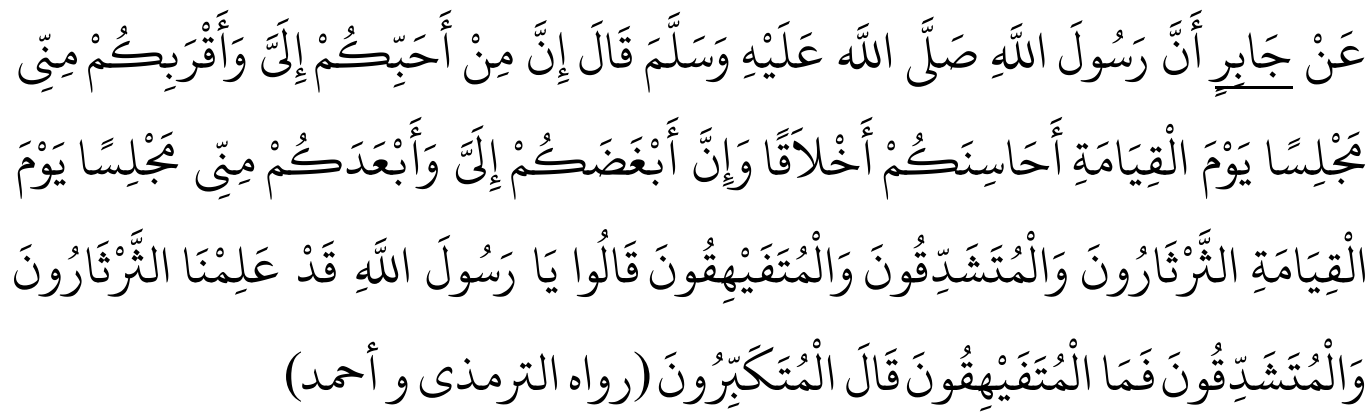

Artinya:

Dari Jabir: sesungguhnya Rasulullah SAW berkata:"Sesungguhnya termasuk orang yang paling kucintai dan dekat kedudukannya denganku pada hari kiamat adalah yang

25 George R. Terry \& Leslie W. Sue, Dasar-Dasar Manajemen. Terj. G.A Ticoalu. (Jakarta:PT Bumi Aksara, 1992), hal. 29

${ }^{26}$ Ahidul Asror, Paradigma Dakwah Konsepsi dan Dasar Pengembangan Ilmu, hal. 100102. 
paling bagus akhlaknya. Sesungguhnya yang paling kubenci dan jauh kedudukannya dariku pada hari kiamat adalah orang-orang yang banyak bicara sehingga keluar darial-haq, lancang mulutnya dan mutafaihiqun." Mereka bertanya: "Wahai Rosulullah, siapa itu mutafaihiqun?" Beliau menjawab:"Orang-orang yang menyombongkan diri." (HR Tirmidzi no 1941 dan Ahmad no. 217)

Hadits tersebut terdapat pada sunan turmudzi Bab birru no. 70 dan kitab imam ahmad bin hanbal jilid 4 hal. 163- 164. ${ }^{27}$ Dari hadits tersebut bisa kita simpulkan bahwa dalam menyampaikan dakwahnya harus menghindari katakata yang keluar dari haq (hoaks), lancang mulutnya (hate speech), dan menyombongkan diri (arogan). Ketiga larangan itu sudah diatur dalam undang-undang negara kita, termasuk arogansi yang bisa menjurus ke perbuatan tidak menyenangkan atau pencemaran nama baik. Untuk itu rambu-rambu dakwah perlu dikuasai oleh para da'i. Tak hanya rambu-rambu, para da'i juga bisa menerapkan media dan metode yang berbeda-beda dalam dakwah.

Seorang daí harus berhati-hati dalam menyampaikan isi dakwah melalui lisannya. Selaras terhadap hadits tersebut, Imam Al Ghozali memberi ramburambu khusus bagi seorang daí dalam menyampaikan dakwah bil lisan, yaitu menjaga lisannya dari 8 hal:

1) Berbohong

2) Ingkar janji

3) Mengumpat/membahas aib orang lain

4) Berdebat

5) Menganggap baik diri sendiri

6) Melaknat

7) Mendoakan jelek terhadap sesama makhluk

8) Bergurau dan mengejek. 28

Kedelapan larangan tersebut seharusnya menjadi rambu-rambu bagi seorang dai dalam membuat bahan atau materi dakwah. Terlebih lagi untuk menghindari kekacauan yang terjadi pada masa sekarang akibat daí yang melakukan ujaran kebencian dan menyebarkan berita hoax untuk kepentingan golongan masing-masing.

Terkhusus untuk dakwah bil lisan, faktor-faktor yang mempengaruhi pemilihan metode dengan mengetahui prinsip-prinsip metode atau pedoman

27 Arent Jan Weinsink.Mu'jam Mufahras li Alfadhil Hadits An Nabawi jilid 1 (Leiden: E.J Brill,1936), hal. 202.

${ }^{28}$ Imam Al Ghozali, Tuntunan mencapai Hidayah Ilahi (terjemahan Bidayatul Hidayah) terj. M. Fadlil Saíd An Nadwi, (Surabaya: Al Hidayah, 1998), hal. 132-148. 
dasar suatu metode. Seorang da'i akan memperhatikan pula faktor-faktor yang mempengaruhi pemilihan dan penggunaan suatu metode agar metode yang dipilih sesuai dengan fungsinya. Berdasarkan QS. An-Nahl:25 telah kita ketahui bahwa dari ketiga metode dakwah bil-hikmah (keilmuan dan kearifan), wa almau'idhat al-hasanah (pendidikan, edukasi), wa jadilhum bilatihiya ahsan (diskusi, kajian ilmiah, dialogis), ${ }^{29}$ maka dakwah melalui media lisan (dakwah bil lisan) bisa kita terapkan pada ketiga metode tersebut.

Adapun faktor-faktor yang mempengaruhi pemilihan metode adalah tujuan. Hal-hal yang dipertimbangkan diantaranya adalah sasaran dakwah, baik masyarakat atau individual dengan segala kebijakan/politik pemerintah, tingkat usia, pendidikan, perdaban (kebudayaan) dan lain sebagainya. Situasi dan kondisi yang beraneka ragam dengan keadaannya. Media dan fasilitas (logistik) yang tersedia, dengan berbagai macam kuantitasnya. Kepribadian dan kemampuan seorang da'i atau muballigh. Semua hal yang terkait dalam kegiatan dakwah harus berjalan dengan seimbang agar memperoleh hasil yang maksimal.

\section{c. Evaluasi}

Evaluasi adalah tahap terakhir dalam manajemen dakwah bil lisan. Secara bahasa, evaluasi berasal dari bahasa inggris, yaitu evaluation. Sedangkan menurut Zainal Arifin, dalam bahasa arab, evaluasi biasa disebut dengan taqwim (تقويم), taqyim (تقييم), atau taqdir (تقدير). Usamah Zaki al Sayid Ali menjelaskan istilah evaluasi dalam beberapa istilah, yaitu al iktibar (examination), al qiyas (measurement), al taqyim (assessment), dan al taqwim (evaluation). Setelah proses evaluasi ini, sebaiknya ada rencana tindak lanjut, khususnya untuk memperbaiki temuan-temuan dari kelemahan, kegagalan, ketidaksempurnaan dalam pelaksanaan program atau rencana. ${ }^{30}$ Selain itu, dalam proses evaluasi perlu adanya ukuran-ukuran atau nilai yang harus dihitung. Sehingga evaluasi juga biasa disebut sebagai (حسب-يحسب-حسب) yang berarti menghitung. Dari pengertian tersebut dapat kita simpulkan bahwa evaluasi adalah menilai atau menghitung kembali apa yang sudah dilakukan dan melakukan perbaikan untuk program selanjutnya.

${ }^{29}$ Nur Alhidayatillah. Dakwah Dinamis Di Era Modern (Pendekatan Manajemen Dakwah). Jurnal An-Nida' Vol. 41 No. 2. (Riau:LPPM Universitas Negeri Sultan Syarif Kasim, 2017), hal. 273.

30 Zainal Arifin, Tafsir Ayat-Ayat Manajemen, (Yogyakarta:Prodi Manajemen Pendidikan Islam UIN Sunan Kalijaga), hal. 156-166. 
Penting bagi seorang da'i untuk mengevaluasi apa yang sudah disampaikan. Baik itu sudah berhasil disampaian maupun yang gagal untuk disampaikan. Rasulullah memerintahkan pada kita untuk berintospeksi diri (mengevaluasi) terhadap segala hal dalam haditsnya:

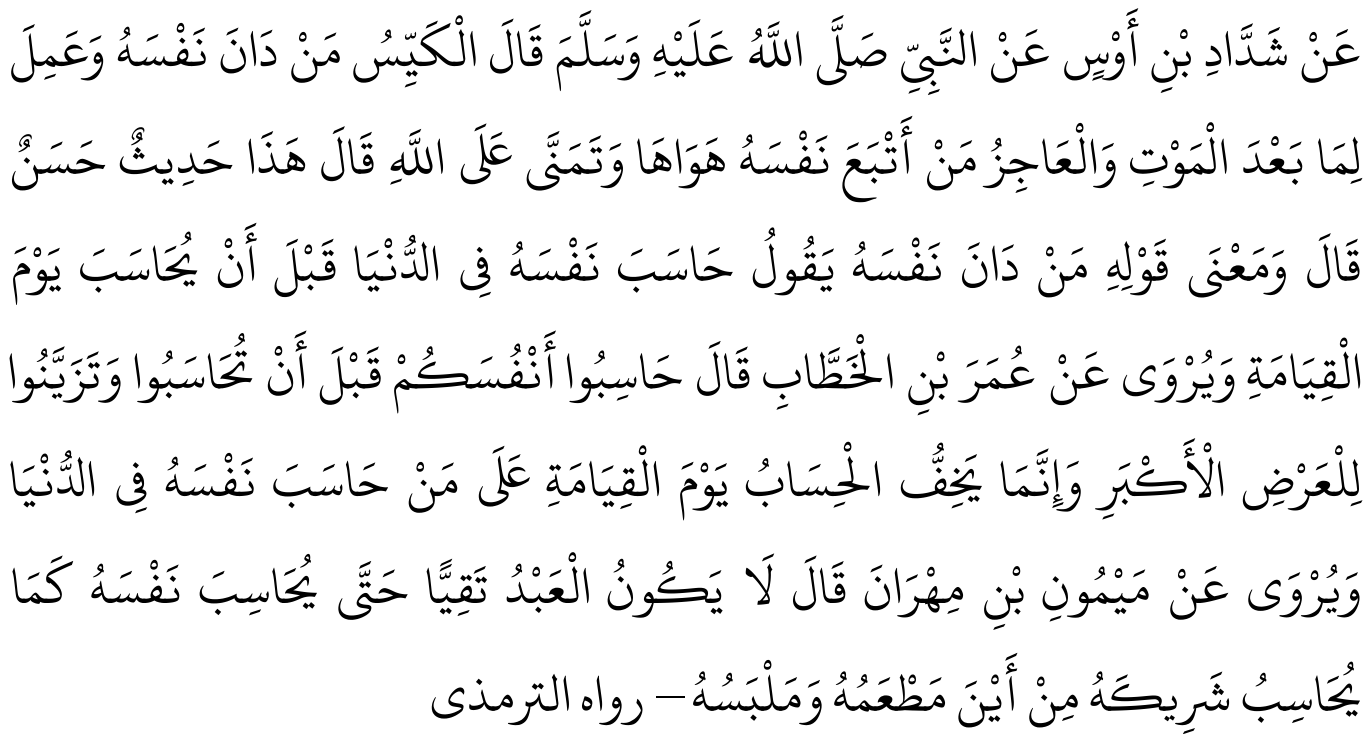

Artinya:

"Dari Syaddad bin Aus dari Nabi SAW bersabda, "Orang yang cerdas itu adalah orang yang mengalahkan hawa nafsunya (dirinya) dan melakukan perbuatan untuk (kehidupan setelah mati), sedangkan orang yang lemah adalah orang yang mengikuti hawa nafsunya dan berangan-angan kepada Allah (berharap akan takdir-Nya). Sufyan berkata" ini hadits hasan" berkata lagi maksud" Man daana Nafsahu" adalah mengevaluasi dirinya di dunia sebelum di hisab nanti di hari kiamat. Dan diriwayatkan dari Umar bin Khattab berkata" Evaluasi diri kalian sebelum dihisab di Akhirat dan berhiaslah untuk kehormatan yang besar dan bahwasanya hisab pada hari kiamat diringankan bagi orang yang mengevaluasi dirinya di dunia. Diriwayatkan juga dari Maimun bin Mihran berkata" Tidak dikatakan hamba yang bertaqwa, sehingga ia mengevaluasi dirinya sebagaimana menginterogasi temannya dari mana dia mendapat makanan dan pakaian. (HR. Turmudzi no. 2383).

Berdasarkan Mu'jam Al Mufahrosh, hadits diriwayatkan oleh At-Tirmidzi bab Qiyamat 25, Ibnu Majah bab Zuhud 21, dan kitab Imam Ahmad bin Hambal juz 4 halaman $124 .{ }^{31}$ Dalam sunan turmudzi, hadits tersebut diceritakan dari sanad Sufyan bin Waki', dari Isa bin Yunus dari Abi Bakar bin

${ }^{31}$ Arent Jan Weinsink.Mu'jam Mufahras li Alfadhil Hadits An Nabawijilid 2 (Leiden: E.J Brill,1936), hal. 163. 
Abi Maryam dari Abdullah bin Abdurrahman, dari kami Amr bin Aun, dari Ibnul Mubarak, dari Abi Bakar bin abi Maryam dari Dlamrah bin Habib.

Dari hadits tersebut, Rasulullah menyuruh kita untuk mengevaluasi diri terhadap apa yang sudah dilakukan juga tetap mengendalikan hawa nafsu. Konsep mengendalikan dalam bentuk evaluasi ini adalah sebagai bahan perbaikan terhadap apa yang akan diucapkan dalam berkomunikasi. Dalam dakwah, kesalahan pasti ada karena manusia memang tempatnya salah dan lupa, oleh karena itu penting untuk dievaluasi agar pesan dakwah yang disampaikan bisa berhasil diterima oleh khalayak. Senada dengan hal tersebut, Sufflebeam dan Shinkfield memaparkan bahwa:

"Evaluation is the process of delineating, obtaining, and providing descriptive and judgmental information about the worth and merit of some object's goals, design, implementation, and impact in order to guide decision makig, serve needs for accountability, and promote understanding of the involved phenomena." 32

Dari penjelasan Stufflebeam \& Shinkfied bisa simpulkan bahwa Evaluasi adalah proses menggambarkan, memperoleh, dan memberikan informasi deskriptif dalam komunikasi dakwah. Hal itu semua diperlukan dalam rangka memandu pembuatan keputusan untuk merencanakan strategi yang lebih baik lagi dalam mencapai tujuan dakwah.

Dari ketiga tahapan tersebut, jelas penting bagi seorang da'i untuk menguasai manajemen dakwah agar tujuan dakwah dapat terlaksana dengan baik. Strategi Rasulullah tersebut selaras dengan teori Manajemen pembelajaran Jacobsen, Eggen, dan Kauchak yang memaparkan : the basic steps in management of teaching which is planning, implementation, and evaluating. ${ }^{33}$ Dari teori tersebut, tiga hal yang harus dikuasai dalam manajemen dakwah adalah perencanaan, implementasi dan evaluasi.

\section{PENUTUP}

Dari hasil pembahasan, dapat kita simpulkan bahwa seorang da'i seyogyanya tidak hanya menguasai materi dan ilmu komunikasi saja, namun juga ilmu manajemen dakwah yang akan sangat berguna untuk diterapkan sesuai tuntunan hadits Rasulullah.

Manajemen dakwah adalah proses perencanaan tugas, mengelompokkan

${ }^{32}$ Stufflebeam, DL, \& AJ Shinkfied, Systematic Evaluation (Boston:Kluwer Nijhof Publishing, 1985), hal. 159.

${ }^{33}$ David A. Jacobsen, Paul Eggen, dan Donald Kauchak, Method for Teaching, Metodemetode Pengajaran,terj. Achmad Fawaid dan Khoirul Anam, (Yogyakarta:Pustaka Pelajar, 2009), hal. 20. 
tugas, menghimpun dan menempatkan tugas dan kemudian menggerakkan kearah pencapaian tujuan dakwah. Terdapat tiga tahapan dalam mengatur kegiatan dakwah sesuai hadits nabi, yaitu:

a. Perencanaan, berdasarkan hadits riwayat Muslim no.69 dengan membuat perencaan dalam menyusun strategi dakwah yang sekiranya tidak menyulitkan, bisa memberi kegembiraan, dan tidak membuat obyek yang kita ajak tidak pergi meninggalkan kita

b. Implementasi, berdasarkan HR Tirmidzi no 1941 dan Ahmad no. 217 yang menuntun da'i bahwa dalam menyampaikan dakwahnya harus menghindari kata-kata yang keluar dari haq (hoaks), lancang mulutnya (hate speech), dan menyombongkan diri (arogan).

c. Evaluasi, berdasarkan HR. Tirmudzi no. 2383 Rasulullah menyuruh kita untuk mengevaluasi diri terhadap apa yang sudah dilakukan juga tetap mengendalikan hawa nafsu

Dengan menguasai manajemen dakwah, maka kegiatan dakwah bisa terlaksana dengan baik, efektif, dan efisien.

\section{Daftar Pustaka}

Al Ghozali, Imam. 1998. Tuntunan mencapai Hidayah Ilahi (terjemahan Bidayatul Hidayah) terj. M. Fadlil Saíd An Nadwi, Surabaya: Al Hidayah,

Alhidayatillah, Nur. 2017. Dakwah Dinamis Di Era Modern (Pendekatan Manajemen Dakwah). Jurnal An-Nida' Vol. 41 No. 2. Riau:LPPM Universitas Negeri Sultan Syarif Kasim

Al Muthlaq, Ibrahim bin Abdullah. 2008. At-Tadarruj Fi Da'wah an-Nabi Sallallahu Alaihi wa Sallam. Terj. Abdul Majid. Yogyakarta:Pustaka Insan Madani

Amin, Samsul Munir.2018. Rekonstruksi Pemikiran Dakwah Islam. Jakarta: Amzah

Anis, Ibrahim et. All. 1972. Al-Mu'jam al-Wasith, Mesir: Dar'1 Ma'arif, Jilid ke1 , cet. ke- 2

Arifin, Zainal. 2019. Tafsir Ayat-Ayat Manajemen, Yogyakarta:Prodi Manajemen Pendidikan Islam UIN Sunan Kalijaga

Asror, Ahidul.2018. Paradigma Dakwah Konsepsi dan Dasar Pengembangan Ilmu, Yogyakarta:LKIS

Atabik, Ahmad.2016. Manajemen Dakwah Perspektif Al-Qur'an,Jurnal TADBIR Vol. 1, No. 1, Juni 2016, STAIN Kudus,

Aziz, Jum'ah Amin Abdul,. 2010. Fiqih Dakwah.Solo: Era Intermedia, 
Griffin, Ricky W.. 2002. Management Seventh Edition. Boston Houston Mifflin Company

Hasan, Hasan Abdullah.2002. Sejarah dan Kebudayaan Islam, terj, H. A. Bahaudin, Jakarta: Kalam Mulia,

Hornby, A.S. 2005. Oxford Advanced Learner's Dictionary Of Current English Seventh Edition.Oxford:Oxford University Press

I'anatut Thoifah. 2015. Manajemen Dakwah Sejarah dan Konsep. Malang:Madani Press,

Jacobsen, David A., Eggen, Paul, dan Kauchak, Donald. 2009. Method for

Teaching, Metode-metode Pengajaran, terj. Achmad Fawaid dan Khoirul Anam, Yogyakarta:Pustaka Pelajar,

Munir, M. dan Ilaihi, Wahyu. 2006. Manajemen Dakwah. Jakarta:Prenada Media. Robbins, Stephen P. \& Coulter, Mary. 2012. Management. Elevent Edition, New Jersey: Pearson Education Publishing inc,

Nawawi, Imam. 1994.Syarah Shahih Muslim, terj. Wawan Djunaedi Soffandi .Jakarta:Mustaqim

Stufflebeam, DL, \& Shinkfied, AJ. 1985. Systematic Evaluation Boston:Kluwer Nijhof Publishing,

Terry, George R. \& Sue, Leslie W., 1992. Dasar-Dasar Manajemen. Terj. G.A Ticoalu. Jakarta:PT Bumi Aksara,

Weinsink, Arent Jan. 1936. Mu'jam Mufahras li Alfadhil Hadits An Nabawi Leiden: E.J Brill 